\title{
The Warning on Saturated Fat: From Defective Experiments to Defective Guidelines
}

\author{
Fabian M. Dayrit* \\ Department of Chemistry, School of Science and Engineering, Loyola Schools, Ateneo de Manila University, \\ Katipunan Ave., Loyola Heights, Quezon City 1108
}

This article was written in response to the advisory published by the American Heart Association (AHA) warning the public against the use of coconut oil due to its saturated fat content (Sacks FM, Lichtenstein AH, Wu JHY, Appel LJ, Creager MA, Kris-Etherton PM, et al. Dietary Fats and Cardiovascular Disease: A Presidential Advisory From the American Heart Association. Circulation. 2017;136(3):e1--e23.).

This article was first published in the websites of the Asian Pacific Coconut Community (www.apccsec.org) and the Integrated Chemists of the Philippines (www.icp.org.ph). Dr. Fabian Dayrit is also the chairman of the Scientific Advisory Committee for Health of the Asian and Pacific Coconut Community and the president of the Integrated Chemists of the Philippines.

\begin{abstract}
Coconut oil has been adversely affected by the current dietary guidelines that advocate a lowering of total fat and the replacement of saturated fat with polyunsaturated fat. This recommendation has its origins in the saturated fat-cholesterol-heart disease hypothesis that Ancel Keys first proposed in 1957. This hypothesis became an official recommendation with the publication of the Dietary Guidelines for Americans in 1980 and has been adopted by many other countries and international agencies. The dietary recommendations also warn against coconut oil. Recently, the American Heart Association re-issued this warning in its 2017 Presidential Advisory. However, a critical review of the experiments that Keys conducted has revealed experimental errors and biases that cast serious doubt on the correctness of his hypothesis and the warnings against coconut oil. Further, the recommendation to decrease saturated fat recommendation effectively means an increase in unsaturated fat in the diet. The actual result has been an increase in omega- 6 fats and a high omega- 6 to omega- 3 fat ratio. This unhealthy ratio has been linked to heart disease, the very disease that the AHA wants to target, as well as cancer and inflammatory diseases. Defective experiments have led to defective guidelines. This first paper in this series of papers will present these errors and biases and address the points raised by the AHA.
\end{abstract}

Abbreviations: AHA: American Heart Association; CHD: coronary heart disease; CVD: cardiovascular disease; HFCS: high fructose corn syrup; MCS: Minnesota Coronary Survey; PUFA: polyunsaturated fatty acid; SDHS: Sydney Diet Heart Study; SFA: saturated fatty acid

\section{INTRODUCTION: THE DIETARY GUIDELINES}

The Vital Statistics of the United States 1976 listed "diseases of heart" as the leading cause of death in the US (USDHHS, 1980). From 1980 to 2015, there were eight editions of the Dietary Guidelines for Americans which sought to address the problem 
of heart disease. In all eight editions of the Dietary Guidelines, there was one warning that was consistent: "Decrease overall fat intake and replace saturated fat with unsaturated fat." However, in 2016, heart disease continued to be the leading cause of death in the US (CDC, 2016). In its 2017 Presidential Advisory, the American Heart Association continued to emphatically recommend that "lowering intake of saturated fat and replacing it with unsaturated fats, especially polyunsaturated fats, will lower the incidence of CVD (Sacks et al., 2017).

Albert Einstein famously defined insanity as: "doing the same thing over and over again and expecting different results." This essay aims to show how the Dietary Guidelines and the AHA recommendation are examples of insanity.

The warning against "saturated fat" is virtually the same recommendation that Ancel Keys made in the 1950s. The Keys hypothesis, generally known as the saturated fat-cholesterol-heart disease hypothesis, states that saturated fats raise serum cholesterol which in turn increases the risk for heart disease. Although the saturated fats that are most often studied are animal fats, coconut oil is often included in this warning because it is a saturated fat.

This first paper will discuss the basis for the recommendations against coconut oil and saturated fat. We will review of the work of Ancel Keys which reveals several errors that invalidate his strictures against coconut oil.

\section{ERRORS IN THE KEYS EXPERIMENTS}

Keys committed several serious errors that cast doubt on the validity of his saturated fat-cholesterol-heart disease hypothesis with respect to coconut oil. He conducted both human feeding and observational studies. In his human feeding studies, Keys used hydrogenated coconut oil, while in his observational studies coconut oil was only a minor component of the population's diet. Finally, Keys was never able to unambiguously prove his hypothesis and refused to acknowledge results that contradicted his hypothesis.

\section{KEYS USED HYDROGENATED COCONUT OIL IN HIS HUMAN FEEDING STUDIES}

In 1957, Keys published two important papers, one in the Journal of Nutrition (Anderson, Keys \& Grande, 1957) and the other in Lancet (Keys, Anderson, Grande, 1957) on controlled feeding studies using schizophrenic patients from the Hastings State Hospital, businessmen in Minnesota, and Japanese coalminers in Shime, Japan. These were relatively small, short-term feeding studies with the number of subjects ranging from 16 to 66 . In these studies, Keys wanted to compare the effects on serum cholesterol of feeding monounsaturated and polyunsaturated fats versus saturated fats. For sources of unsaturated fats, he used corn oil, olive oil, cottonseed oil, safflower oil, and sardine oil. For sources of saturated fats, he used butterfat, margarine and hydrogenated coconut oil (Hydrol) in the Minnesota experiment and margarine in the Shime experiment.

The use of hydrogenated fats - margarine and Hydrol - in this feeding study casts doubt on the validity of the conclusions of this work regarding the effects of coconut oil. It was already known in the 1920s that hydrogenation of vegetable oils produced trans fats (Hilditch \& Vidyarthi, 1929). In 1957 , the same year when both Keys papers came out, it was reported that trans fats were deposited in various human tissues, such as adipose tissues, liver, aortic tissue, and atheroma of those who died of atherosclerosis (Johnston, Johnson, Kummerow, 1957). In a 1961 paper on hydrogenated fats, Keys himself noted that hydrogenated oils raised serum cholesterol and triglycerides (Anderson, Grande, Keys, 1961). Therefore, the increase in serum cholesterol that Keys observed may have been due to the trans fats in margarine and hydrogenated coconut oil and this would make his conclusions invalid. The use of hydrogenated coconut oil may also have biased Keys's judgment against coconut oil.

\section{THE SEVEN COUNTRIES STUDY WAS NOT A REPRESENTATIVE STUDY}

Keys described the evolution of the Seven Countries Study in a book that he published in 1980. Keys conducted initial studies on CHD in 1947 in Minnesota on healthy businessmen and professionals. In 1952, this study expanded to include Italy and Spain, in 1956, Japan and Finland. The aim of these studies was to identify dietary and lifestyle factors in apparently healthy middleaged men that contributed to CHD. However, this study had two built-in limitations which would give results that are not representative. First, to ensure higher probability of successful follow-up (every 5 years), the study targeted rural populations so that 11 of the 16 cohorts studied were rural populations. For the US, since the stability of rural populations could not be assured, the American subjects selected were railroad men and to balance this effect, Italian railroad men were also selected. Second, the basis for the selection of the seven countries was not systematic but was decided by the availability of collaborators. As Keys himself stated, it was the availability of research collaborators that became 
the deciding factor in the selection of subject areas (Keys, 1980). It is clear that there was no scientific basis for the selection of the seven countries and these limitations should have been declared so that sweeping generalizations could be avoided.

The Seven Countries Study was begun in 1956 and ended with the publication of the 1986 paper (Keys et al., 1986). The most important conclusions from the Seven Countries Study were given as follows:

"Death rates were related positively to average percentage of dietary energy from saturated fatty acids, negatively to dietary energy percentage from monounsaturated fatty acids... All death rates were negatively related to the ratio of monounsaturated to saturated fatty acids... Oleic acid accounted for almost all differences in monounsaturates among cohorts. All-cause and coronary heart disease death rates were low in cohorts with olive oil as the main fat."

There are a number of important things that should be noted regarding the Seven Countries Study: First, this study cannot be claimed to be representative for all types of oils and for all groups of people. Second, the beneficial oil claimed in the Seven Countries Study was olive oil and it should be compared only to the other fats and oils that were consumed, which was mainly animal fat. Interestingly, although Japan showed very low death rates, olive oil consumption in Japan was negligible (Pitts et al., 2007). Third, this study assumed that all saturated fats have the same properties regardless of chain length. This assumption is not valid given what is known today regarding the individual properties of saturated fatty acids (this will be discussed in a succeeding article).

\section{COCONUT OIL WAS NOT A SIGNIFICANT PART OF THE DIET IN THE SEVEN COUNTRIES STUDY}

Coconut oil was not a significant part of the diet in any of the seven countries and it was not mentioned in the 1986 Keys paper. Based on the consumption record for the year 1961, the estimated amount of animal fat consumed in Northern and Southern Europe was $67.5 \%$ and $35.7 \%$, respectively, while for coconut oil, it was $5.9 \%$ and $1.6 \%$. In the US, the amount of animal fat in the diet was $51 \%$ versus 3\% for coconut oil (FAOSTAT, 2006; Pitts et al., 2007). Clearly, coconut oil was an insignificant part of the diet in Europe and the US so how did coconut oil get included in the health warnings on heart disease?

\section{THE LOW-FAT DIET AND OBESITY}

The first official recommendation on saturated fat was contained in the first Dietary Guidelines for Americans which was jointly issued by the US Department of Agriculture and the US Department of Health and Human Services in 1980 and updated every 5 years. From the first to the eighth edition of Dietary Guidelines, the recommendation on saturated fat remained fundamentally the same: consume a low fat diet and avoid saturated fat. In the 2010 edition, the recommendation was made more specific: "consume less than $10 \%$ of calories from saturated fatty acids by replacing them with monounsaturated and polyunsaturated fatty acids."

Cohen and co-workers (2015) conducted a comprehensive analysis of the food consumption patterns together with the body weight and body mass index of the US adult population using data from the US National Health and Nutrition Examination Survey (NHANES). They found that Americans in general have been following the nutrition advice from the Dietary Guidelines. In particular from 1971 to 2011, consumption of fats dropped from $45 \%$ to $34 \%$ of total caloric intake, but this was accompanied by an increase in carbohydrate consumption from $39 \%$ to $51 \%$. The result was a dramatic increase in the percentage of overweight or obese Americans from $42 \%$ to $66 \%$ over the same period. It is surprising that the AHA would continue to recommend the "low-fat diet" in light of the obesity epidemic among Americans.

\section{KEYS FAILED TO PROVE HIS SATURATED FAT-CHOLESTEROL- HEART DISEASE HYPOTHESIS}

Since the Seven Countries Study was an observational study, Keys wanted to do a study where he could carefully control the diet of the subjects. In 1967, Ivan Frantz, Jr. and Ancel Keys undertook a project entitled "Effect of a Dietary Change on Human Cardiovascular Disease," also called the "Minnesota Coronary Survey" (MCS). This study was funded by the US National Heart, Lung and Blood Institute and was undertaken from 1968 to 1973. MCS was meant to be a landmark study because of the large number of subjects $(n=9,423)$, the length of the feeding study (5 years), the high level of dietary control, and the double blind randomized design. MCS used residents in a nursing home and patients in six state mental hospitals in Minnesota. This enabled the study to carefully control and document the food that was actually consumed. This study sought to test whether replacement of saturated fat (animal fat, margarines and shortenings) with vegetable oil rich in linoleic acid (mainly corn oil) will reduce all-cause death, and CHD in particular, by lowering serum cholesterol. Coronary atherosclerosis and myocardial infarcts were also checked in 149 
autopsies conducted (Ramsden et al., 2016). This study was conducted at the same time that Keys was coordinating the Seven Countries Study and would have provided powerful validation of the saturated fat-cholesterol-heart disease hypothesis.

Unfortunately, Keys did not publish the results of this study. A partial release of the results of MCS study was made in a 1989 paper in the journal Arteriosclerosis with Frantz as lead author. This paper made the modest conclusion that: "For the entire study population, no differences between the treatment (high linoleic acid group) and control (high saturated fat group) were observed for cardiovascular events, cardiovascular deaths, or total mortality." (Frantz et al., 1989). Interestingly, although Keys was a co-proponent of the MCS study, his name did not appear as a co-author in the Arteriosclerosis paper; he was not even mentioned in the Acknowledgment.

The full data were discovered in the basement of the home of Frantz by his son, Robert, who turned them over to Ramsden and co-workers, who then analyzed and interpreted the data (O'Connor, 2016). The key results from the MCS study were reported by Ramsden and co-workers (2016) and are summarized as follows:

- The group that consumed the high linoleic acid diet showed significant reduction in serum cholesterol compared with those on the saturated fat group.

- However, there was no difference in mortality among the groups.

- There was a higher risk of death in subjects who showed reduction in serum cholesterol level.

- The main conclusions from this study are as follows: a high linoleic acid diet effectively lowers serum cholesterol but this increases the risk of $\mathrm{CHD}$.

The results of the MCS study did not give the expected results and directly contradicted the conclusions of the Seven Countries Study which Keys had published in a few years earlier in 1986. This might explain why it was published in a journal of limited circulation which gave it less exposure. It is clear that a wider distribution of the results of the 1989 paper, with Keys properly included as co-author, would have been fatal to the saturated fat-cholesterol-heart disease hypothesis and to the scientific basis of Dietary Guidelines, which was going into its third edition.

The recovered MCS study is not the only example of an unreported study which had negative results. The Sydney Diet Heart Study (SDHS) was conducted from 1966 to 1973 , almost at the same time as the MCS study, with the same objectives and similar study design to evaluate the effectiveness of replacing dietary saturated fat with linoleic acid for the prevention of CHD and all-cause mortality. This was a single blinded, parallel group, randomized controlled trial involving 458 men aged 30-59 years with a recent coronary event. The intervention involved replacement of dietary saturated fats (from animal fats, common margarines, and shortenings) with omega-6 linoleic acid (from safflower oil and safflower oil polyunsaturated margarine). The primary outcome was all-cause mortality and the secondary outcomes were $\mathrm{CHD}$ and death from heart disease. The results of this study were contrary to expectation: the unsaturated fat group had higher rates of death than the animal fat group, both in terms of all-cause mortality and CVD mortality. Similar to the recovered MCS study, the SDHS data were not reported but were recovered for analysis by Ramsden and co-workers almost 40 years after it was conducted (Ramsden et al., 2013).

In addition to the hidden MCS and SDHS studies, there are a number of published studies that contradicted the saturated heart-cholesterolheart disease hypothesis. A six-year dietary study of 21,930 Finnish men, aged 50-69 years, concluded that there was no association between the intake of saturated fat and monounsaturated fat with the risk of coronary death (Pietinen et al., 1997). A dietary study of 80,082 women in the US Nurses' Health Study, aged 34-59 years, with a 14-year follow-up, failed to come up with an unambiguous conclusion on the link between saturated fat and CHD ( $\mathrm{Hu}$ et al., 1999). A study involving 58,453 Japanese men and women, aged 40-79 years, with a 14- year followup, gave an inverse association between SFA intake and mortality from total cardiovascular disease and concluded that replacing SFA with PUFA would have no benefit for the prevention of heart disease (Yamagishi et al., 2010).

One would think that these studies should be enough evidence to prove that the saturated fat-cholesterolheart disease hypothesis is wrong. Unfortunately, the 2017 AHA Presidential Advisory did not cite these studies and instead went out of its way to discredit the results of the Minnesota Coronary Survey and the Sydney Diet Heart Study so that they could remove these studies from the "totality of the scientific evidence (that) satisfy rigorous criteria for causality."

In 1981, Steven Broste, who was then a MS student at the University of Minnesota, analyzed the MCS data and addressed the difficulties that the AHA used to reject this study. These issues included 
withdrawals and uneven feeding periods of subjects. After making the appropriate statistical corrections, Broste still came to the conclusion that: "the experimental diet of the MCS may actually have been harmful in some way to patients who were exposed to it for at least one year" (Broste, 1981, p 85 ), and that "the experimental diet of the MCS, and reductions in cholesterol that resulted from the diet, were counterproductive... cholesterol reductions were generally associated with increased mortality, especially among males and older patients" (Broste, 1981, p 97). Broste's conclusions were consistent with those of Frantz and co-workers (1989) and Ramsden and co-workers (2016). Contrary to the claims of the AHA, the MCS results are valid: low serum cholesterol increases the risk of CHD. It is unfortunate that the AHA chose to dismiss the results of the MCS and SHDS studies as lacking in scientific rigor.

\section{HIGH PUFA CONSUMPTION AND HIGH OMEGA-6 TO OMEGA-3 RATIO: A DIETARY DISASTER}

The low-fat and low-saturated fat recommendation of the Dietary Guidelines may be the reason for rising obesity, diabetes, and other metabolic diseases among Americans. The low-fat recommendation has effectively increased the consumption of sugar and carbohydrates. Since 1980, consumption of fats fell by $11 \%$ of total caloric intake (from $45 \%$ to $34 \%$ ), while consumption of carbohydrates rose by $12 \%$ (from $39 \%$ to $51 \%$ ) (Cohen et al., 2015). The consumption of soybean oil, a high omega- 6 polyunsaturated oil, more than doubled during the same period and now accounts for over $90 \%$ of vegetable oil consumption in the US (Index Mundi, 2016). Because soybean oil is a polyunsaturated oil, it is susceptible to the formation of free radicals, malondialdehyde, trans fats, and polymeric material during frying (Brühl, 2014).

The other major problem with the Dietary Guidelines is that it has resulted in a diet with excessive omega- 6 fatty acid resulting in an average omega- 6 to omega-3 ratio of about 15:1. Such a high ratio has been blamed for cardiovascular disease, cancer, and chronic inflammatory, and autoimmune diseases. The ideal omega- 6 to omega- 3 ratio is about $4: 1$ (Simopoulos 2002, 2008, 2010).

AHA should worry about the impact of too much soybean oil - not coconut oil - on the American diet. It should also rethink its support for the Dietary Guidelines.

\section{FROM DEFECTIVE EXPERIMENTS TO DEFECTIVE GUIDELINES}

Despite its widespread adoption, the saturated fat-cholesterol-heart disease hypothesis has been shown to be incorrect. Ancel Keys committed a number of errors and was unable to unambiguously demonstrate a causal link for the role of saturated fat in heart disease. The twenty-five year old, 8-edition Dietary Guidelines for Americans, which has a great influence on international guidelines, has failed to address the problem of heart disease. Defective experiments can only lead to defective guidelines, and defective guidelines can only result in poor health outcomes.

\section{REFERENCES}

Anderson JT, GrandeF, Keys A(1961). Hydrogenated Fats in the Diet and Lipids in the Serum of Man. J. Nutr. 75: 388-394.

Anderson JT, Keys A, Grande F (1957). The effects of different food fats on serum cholesterol concentration in man. J Nutr. 62: 421-444.

Broste SK (1981). Lifetable Analysis of the Minnesota Coronary Survey. MS thesis, University of Minnesota.

Brühl L (2014). Fatty acid alterations in oils and fats during heating and frying. Eur. J. Lipid Sci. Technol. 116: 707-715.

[CDC] Center for Disease Control. 2016. https:// www.cdc.gov/dhdsp/data_statistics/fact_sheets/ docs/fs_heart_disease.pdf

[Codex] Codex Alimentarius 210-1999, amended 2015; Codex Alimentarius 33-1981, amended 2013.

Cohen E, Cragg M, deFonseka J, Hite A, Rosenberg M, Zhou B (2015). Statistical review of US macronutrient consumption data, 1965-2011: Americans have been following dietary guidelines, coincident with the rise in obesity. Nutrition 31: 727-732.

[FAOSTAT] Food and Agriculture Organisation Statistics Data. 2006. World lipid availability, Kg/ capita/year, 1961. Food Balance Sheets, Rome: FAO.

Frantz Jr. ID, Dawson EA, Ashman PL, Gatewood LC, Bartsch GE, Kuba K, Elizabeth R. Brewer ER (1989). Arteriosclerosis 9:129-135. 
Hilditch TP, Vidyarthi NL (1929). The products of partial hydrogenation of higher monoethylenic esters. Proc. Roy. Soc. A, 122(790): 552-563.

Hu FB, Stampfer MJ, Manson JE, Ascherio A, Colditz GA, Speizer FE, Hennekens CH, C Willett WC (1999). Dietary saturated fats and their food sources in relation to the risk of coronary heart disease in women. Am. J. Clin. Nutr. 70:10011008.

Index Mundi (2016). http:// www.indexmundi. com/

Keys A, Anderson JT, Grande F (1957). Prediction of serum-cholesterol responses of man to changes in fats in the diet. Lancet 959-966.

Keys A, Aravanis C, Blackburn H, Buzina R, Djordjević BS, Dontas AS, Fidanza F, Karvonen MJ, Kimura N, Menotti A, Mohacek I, Nedeljkovic S, Puddu V, Punsar S, Taylor HL, van Buchem FSP (1980). Seven Countries. A Multivariate Analysis of Death and Coronary Heart Disease. Harvard University Press, Cambridge, Massachusetts.

Keys A, Menotti A, Karvonen MJ, Aravanis C, Blackburn H, Buzina R, Djordjevic BS, Dontas AS, Fidanza F, Keys MH, Kromhout D, Nedeljkovic S, Punsar S, Seccareccia F, Toshima H (1986). The diet and 15-year death rate in the Seven Countries Study. Am. J. Epidemiol. 124(6): 903-915.

O'Connor A (2016). A Decades-Old Study, Rediscovered, Challenges Advice on Saturated Fat. New York Times, April 13, 2016. http://well.blogs. nytimes.com/2016/04/13/a-decades-old-studyrediscovered-challenges-advice-on-saturated-fat/? $\mathrm{r}=0$

Pietinen P, Ascherio A, Korhonen P, Hartman AM, Willett WC, Albanes D, Virtamo J (1997). Intake of Fatty Acids and Risk of Coronary Heart Disease in a Cohort of Finnish Men. Am. J. Epidemiol. 145(10): 876-887.

Pitts M, Dorling D, Pattie C (2007). Oil for Food: The Global Story of Edible Lipids. Journal of WorldSystems Research, Volume XIII, Number 1, Pages 12-32. ISSN 1076-156X.

Ramsden CE, Zamora D, Leelarthaepin B, Majchrzak-Hong SF, Faurot KR, Suchindran CM, Ringel A, Davis JM, Hibbeln JR (2013). Use of dietary linoleic acid for secondary prevention of coronary heart disease and death: evaluation of recovered data from the Sydney Diet Heart Study and updated meta-analysis. BMJ 2013;346:e8707.
Ramsden CE, Zamora D, Majchrzak-Hong S, R Faurot KR, Broste SK, Frantz RP, Davis JM, Ringel A, Suchindran CM, Hibbeln JR (2016). Reevaluation of the traditional diet-heart hypothesis: analysis of recovered data from Minnesota Coronary Experiment (1968-73). BMJ 2016;353:11246 http://dx.doi.org/10.1136/bmj.i1246.

Sacks FM, Lichtenstein AH, Wu JHY, Appel LJ, Creager MA, Kris-Etherton PM, Miller M, Rimm EB, Rudel LL, Robinson JG, Stone NJ, Van Horn LV (2017). Dietary Fats and Cardiovascular Disease, A Presidential Advisory From the American Heart Association. Circulation 135: e1-e24.

Simopoulos AP (2002). The importance of the ratio of omega-6/omega-3 essential fatty acids. Biomed Pharmacother 56(8): 365-79.

Simopoulos AP (2008). The Importance of the Omega-6/Omega-3 Fatty Acid Ratio in Cardiovascular Disease and Other Chronic Diseases. Exp Biol Med 233(6): 674-688.

Simopoulos AP (2010). Genetic variants in the metabolism of omega-6 and omega-3 fatty acids: their role in the determination of nutritional requirements and chronic disease risk. Exp Biol Med 235: 785-795.

[USDA] United States Department of Agriculture (2017). United States Department of Agriculture. Food Composition Databases. https://ndb.nal.usda. gov/; (downloaded: May 15, 2017).

[USDHHS] U.S. Department of Health and Human Services. 1980. Vital Statistics of the United States 1976. Volume II- Mortality. Part A. National Center for Health Statistics. Hyattsville, Maryland.

Vijayakumar M, Vasudevan DM, Sundaram KR, Krishnan S, Vaidyanathan K, Nandakumar S, Chandrasekhar R, Mathew N (2016). A randomized study of coconut oil versus sunflower oil on cardiovascular risk factors in patients with stable coronary heart disease. Ind. Heart J. 68: 498-506.

Yamagishi K, Iso $\mathrm{H}$, Yatsuya $\mathrm{H}$, Tanabe $\mathrm{N}$, Date C, Kikuchi S, Yamamoto A, Inaba Y, Tamakoshi A, (JACC Study Group) (2010). Dietary intake of saturated fatty acids and mortality from cardiovascular disease in Japanese: the Japan Collaborative Cohort Study for Evaluation of Cancer Risk (JACC) Study. Am. J. Clin. Nutr. 92:759-765. 